Volume 2, Nomor 2, Maret 2022, hlm 110-115

BEMAS: JURNAL BERMASYARAKAT

p ISSN 27455866 | e ISSN 27457958

\title{
Sosialisasi Penggunaan Aplikasi E-Learning Berbasis Website Di Masa Pandemi Covid-19
}

\author{
Rofiq Noorman Haryadi ${ }^{1 *}$, Andi Muhamad Yusup ${ }^{2}$, Destiana Utarinda ${ }^{3}$, Indri Ayu Mustika ${ }^{4}$, \\ Dewi Sandra ${ }^{5}$, Dewi Utari Rokhmawati ${ }^{6}$ \\ $1^{*, 2,3,4,5,6}$ STEBIS Bina Mandiri, Cileungsi, Bogor, Jawa Barat, Indonesia 16820 \\ 1,2,3,4,5,6 J1. Raya Cileungsi - Jonggol KM. 1, No. 12, Cileungsi, Bogor, Jawa Barat
}

\begin{tabular}{l} 
INFORMASI ARTIKEI \\
\hline Article History: \\
Submission: $10-12-2021$ \\
Revised:28-12-2021 \\
Accepted: $29-12-2021$ \\
* Korespondensi: \\
Rofiq Noorman Haryadi \\
rofiq@binamandiri.ac.id
\end{tabular}

\begin{abstract}
ABSTRAK
Pengabdian masyarakat ini dilakukan bersama mitra SMK Bina Mandiri Multimedia yang berlokasi di Cileungsi dalam hal sosialisasi penggunaan aplikasi yang telah dibuat sebelumnya oleh tim pengabdi dengan dibantu oleh salah satu pendidik dari SMK Bina Mandiri Multimedia. Dalam proses pembuatan aplikasi e-learning berbasis website ini, tim yang dibantu oleh pendidik SMK merancang sebuah aplikasi yang selanjutnya dibuat oleh peserta didik dengan arahan dan panduan dari tim pengabdi. Berdasarkan hasil pengamatan yang dilakukan oleh tim, diperoleh kesulitan bagi sebagian warga sekolah untuk melakukan kegiatan belajar mengajar. Secara umum penggunaan metode pada PkM ini adalah dengan memberikan pengetahuan dan pendampingan berupa sosialisasi kepada pendidik dan peserta didik dalam menjalankan aplikasi tersebut. Hasil PkM ini adalah sebuah aplikasi berbasis website yang disesuaikan dengan kebutuhan dari proses pembelajaran yang mana aplikasi ini diberi nama "Daring BM3". Adapun target tujuan luaran yang diharapkan dari kegiatan ini adalah memberikan pengetahuan kepada peserta didik untuk dapat mengembangkan kemampuan pengetahuan dalam membuat software baik offline maupun online.
\end{abstract}

Kata kunci: Sistem Pembelajaran, Belajar Online, Website, SMK BM3

A SOCIALIZATION OF THE USE OF WEBSITE-BASED ELEARNING APPLICATIONS IN THE COVID-19 PANDEMIC

\begin{abstract}
This community service is carried out with partners from SMK Bina Mandiri Multimedia located in Cileungsi in terms of socializing the use of applications that have been made previously by the service team with the assistance of one of the educators from SMK Bina Mandiri Multimedia. In the process of making this website-based e-learning application, a team assisted by vocational educators designed an application which was then made by students with directions and guidance from the service team. Based on observations made by the team, it was found that it was difficult for some school residents to carry out teaching and learning activities. In general, the use of the PkM method is to provide knowledge and assistance in the form of socialization to educators and students in running the application. The result of this PkM is a website-based application that is tailored to the needs of the learning process where this application is named "Daring BM3". The external target expected from this activity is to provide knowledge to students to be able to develop knowledge skills in making software both offline and online.
\end{abstract}


Keywords: E-Learning, Online Learning, Website, SMK BM3

\section{PENDAHULUAN}

Perkembangan sebuah teknologi yang sangat maju seperti sekarang ini, menuntut masyarakat harus mampu mengimbangi kemajuannya. Kemajuan teknologi yang mengglobal ini sangat berpengaruh pada semua aspek-aspek kehidupan terlebih para pelajar yang pada dasarnya harus mengikuti perkembangan teknologi di era milenium pada semua aspek pembelajaran. Pandemi Covid-19 memaksa orang untuk tinggal di rumah bahkan saat beraktifitas pun ikut menjadi sorotan penting akan perkembangannya. Para peserta didik melakukan aktifitas belajar dari rumah dan pendidik harus mengajar dari rumah juga.

Sebagai salah satu SMK bidang IT di Cileungsi menuntut warga sekolahnya untuk dapat menggunakan teknologi untuk membantu proses pembelajaran, sesuai dengan yang dikemukakan oleh Sihotang perlu adanya pembelajaran berbasis teknologi yang mampu meningkatkan kualitas pendidikan, yang pada salah satunya berbasis web[1]. Tentu dengan adanya teknologi yang menunjang pembelajaran, akan dapat meningkatkan kemampuan dan pengetahuan peserta didik. Senada dengan [2] bahwa dalam melaksanakan belajar mengajar jarak jauh, teknologi tentu menjadi tolak ukur keberlangsungan pembelajaran yang menghubungkan antara guru dan siswa yang terpisah oleh jarak. Agar aplikasi dapat digunakan dengan baik maka harus dilakukan pengecekan atas sistem operasionalnya dengan baik [3].

Penggunaan teknologi di semua aspek terkhusus bidang pendidikan merupakan salah satu hal yang harus diperhatikan agar proses belajar mengajar dapat dilaksanakan dengan baik oleh pendidik dan peserta didik. Teknologi merupakan salah satu bagian yang mendukung peradaban kebudayaan manusia[4]. Sedangkan penggunaan teknologi informasi dalam proses pembelajaran di kelas, sudah menjadi suatu kebutuhan sekaligus tuntutan di era global[5]. Dengan demikian bahwa teknologi adalah sebuah media untuk mendukung segala hal di era sekarang ini. Sulitnya upaya peserta didik dalam mengikuti proses belajar yang dilaksanakan secara online/daring ini, merupakan sebuah tantangan tersendiri oleh pihak sekolah maupun pendidik dalam memberikan ilmu pengetahuannya. Salah satu hal yang dapat dilakukan untuk proses belajar mengajar ini adalah dengan memberikan mereka pengetahuan serta mendampingi mereka. Dengan kata lain, teknologi adalah sebuah media penyeimbang pengetahuan dengan semua aspek kegiatan yang dilakukan oleh setiap orang untuk tujuan tertentu.

Seiring dengan kemajuan di bidang teknologi yang menyajikan beragam aplikasi pembelajaran berbasis online yang dikembangkan oleh merk-merk ternama yang antara lain; moodle, admodo, google classroom, dan lain sebagainya. SMK Bina Mandiri Multimedia yang memiliki kejuruan Rekayasa Perangkat Lunak mencoba membuat sebuah aplikasi pembelajaran berbasis website dengan mengadopsi beberapa sistem metode pembelajaran online untuk lebih mudah dalam penggunaannya baik oleh pendidik maupun peserta didik. [6] mengemukakan bahwa "Web" adalah salah satu aplikasi yang berisi dokumen multimedia yang dalamnya menggunakan protokol HTTP (hypertext transfer protocol)[7] dan untuk mengaksesnya menggunakan perangkat lunak". Maka, website merupakan media yang mampu memudahkan kegiatan dalam proses belajar mengajar agar dapat lebih menarik. Hal ini serupa dengan [8] Web edutainment dapat membantu pendidik dalam memberikan materi ajar kepada peserta didik agar lebih menarik, interaktif dan bersifat dinamis[9].

Adapun tujuan dari kegiatan PkM ini adalah memberikan kesempatan kepada siswa kejuruan RPL untuk dapat mengembangkan pengetahuan tentang software yang dapat digunakan sebagai media pembelajaran secara online di masa pandemi Covid-19. Dengan adanya suatu aplikasi yang menjadi sebuah model pembelajaran di masa pandemi sekarang ini diharapkan dapat membuat nilai lebih bagi 
112 Rofiq Noorman Haryadi, Andi Muhamad Yusup, Destiana Utarinda, Indri Ayu Mustika, Dewi Sandra, Dewi Utari Rokhmawati

Sosialisasi Penggunaan Aplikasi E-Learning Berbasis Website Di Masa Pandemi Covid-19

sekolah maupun semua siswa kejuruan RPL untuk tetap dapat memaksimalkan ilmu yang diperoleh saat belajar di sekolah.

\section{METODE PELAKSANAAN}

Aplikasi pembelajaran berbasis website ini di design secara sederhana sesuai dengan kebutuhan pendidik maupun peserta didik. Sebelum digunakan, tentu aplikasi ini melalui beberapa serangkaian tes pengujian baik oleh pendidik maupun peserta didik untuk mengetahui tingkat kesalahan sistem yang dibuat. Setelah melakukan beberapa kali pengujian sistem hingga minim kesalahan sistem yang ditemukan. Maka perlu adanya sosialisasi aplikasi tersebut kepada pendidik maupun peserta didik yang diwakili oleh ketua dari masing-masing kelas[10]. Sosialisasi adalah salah satu sarana yang mempengaruhi kepribadian orang lain. Sosialisasi biasa disebut sebagai teori mengenai peranan (role theory).

Karena dalam proses sosialisasi diajarkan peran-peran yang harus dijalankan oleh individu [11]. Sedangkan [12] mengatakan bahwa sosialisasi merupakan proses yang dilakukan setelah kebijakan dibuat sebagai landasan pengetahuan dan pemahaman sebelum proses implementasi kebijakan dilaksanakan. Maka, dengan kata lain sosialisasi adalah sebuah kegiatan yang dapat dilakukan untuk memberikan pengetahuan kepada orang lain dengan melalui proses pemberian pemahaman secara baik dan dapat dimengerti oleh orang lain.

Sosialisasi dilakukan untuk memperkenalkan lebih jauh sistem kerja aplikasi pembelajaran berbasis website dari bagaimana pendidik melakukan upload materi, membuat soal baik latihan maupun ujian, merekap data hasil tugas latihan maupun ujian yang dapat di download berupa Excel dan peserta didik yang membaca materi, mengisi tugas baik latihan maupun ujian dan mendapatkan penilaian hasil yang diberikan oleh pendidiknya[13].

Setelah penggunaan aplikasi digunakan dalam proses pembelajaran selama 1 semester, dimana kegiatan guru dalam melaksanakan kegiatan mengajar secara online, di ruang guru, menggunakan laptop, dan peralatan bantu extended monitor, microphone, smartphone, sound power [14][15]. Tim melakukan evaluasi terhadap kinerja aplikasi tersebut dengan cara membuat beberapa pertanyaan berupa kuesioner yang disebarkan kepada warga sekolah melalui media online google formulir. Pertanyaan terdiri dari 5 kategori penilaian antara lain (1) Penilaian konten yang berisikan pertanyaan terkait isi aplikasi, (2) Antar muka berisikan pertanyaan terkait penggunaan aplikasi , (3) Umpan balik berisikan pertanyaan terkait kemudahan dalam berinteraksi, (4) Personalisasi yang terkait pembelajaran mandiri dan (5) Interaktif terkait komunikasi pendidik dan peserta didik, dimana setiap kategori memiliki 4 pertanyaan dengan pilihan Sangat Sesuai (SS), Sesuai (S), Tidak Sesuai (TS) dan Sangat Tidak Sesuai (STS).

Adapun tujuan dari kegiatan ini untuk mengembangkan kemampuan siswa dalam berkreasi sesuai dengan bidang kejuruannya agar siswa lebih siap dan percaya diri saat memasuki dunia industri dalam membangun atau membuat sebuah aplikasi berupa software yang dapat digunakan secara offline maupun online.

\section{HASIL DAN PEMBAHASAN}

Setelah melakukan sosialisasi dan pengujian serangkaian kegiatan untuk mengetahui tingkat kesalahan sistem aplikasi pembelajaran berbasis website ini baik dari menu administrator, pendidik maupun peserta didik. Maka, secara rinci dijelaskan sebagai berikut:

\subsection{Hasil}

Untuk mengukur kinerja aplikasi ini dilakukan penyebaran kuesioner yang dilakukan pada kegiatan ini secara online menggunakan google formulir kepada pengguna aplikasi yakni pendidik dan peserta didik di lingkungan SMK Bina Mandiri Multimedia yang berlokasi di Cileungsi Jawa Barat. 
Tabel 1. Konten

\begin{tabular}{llcccc}
\hline No & Pertanyaan & $S S$ & $S$ & $T S$ & STS \\
\hline 1 & Sistem aplikasi menyediakan isi yang sangat sesuai dengan kebutuhan & 102 & 152 & 18 & - \\
2 & Sistem aplikasi menyediakan isi yang bermanfaat & 65 & 196 & 11 & - \\
3 & Sistem aplikasi menyediakan isi yang cukup lengkap & 86 & 167 & 19 & - \\
4 & Sistem aplikasi menyediakan isi yang up-to date & 89 & 163 & 18 & 2 \\
\hline & Rata-rata & 86 & 170 & 17 & 2 \\
\hline
\end{tabular}

Dari hasil tabel 1 diperoleh bahwa konten atau isi yang terdapat pada aplikasi ini sudah sesuai yang ditandai dengan hasil rata-rata kuesioner pada Sangat Sesuai (SS) sebesar 43, Sesuai (S) sebesar 85.5, Tidak Sesuai (TS) sebesar 12 dan Sangat Tidak Sesuai (STS) sebesar 2.

Tabel 2. Pertanyaan antarmuka

\begin{tabular}{|c|c|c|c|c|c|}
\hline No & Pertanyaan & $S S$ & $S$ & $T S$ & STS \\
\hline 1 & Sistem e-learning mudah digunakan & 158 & 98 & 14 & 2 \\
\hline 2 & $\begin{array}{l}\text { Sistem e-learning mempermudah saya untk mencari materi } \\
\text { yang saya butuhkan }\end{array}$ & 132 & 108 & 25 & 7 \\
\hline 3 & $\begin{array}{l}\text { Isi yang disediakan e-learning mudah dipahami dan bersifat } \\
\text { user-friendly }\end{array}$ & 205 & 46 & 17 & 4 \\
\hline 4 & Pengoperasian siste e-learning stabil dan lancar & 89 & 167 & 10 & 6 \\
\hline & Rata-rata & 146 & 105 & 17 & 4.75 \\
\hline
\end{tabular}

Dari hasil tabel 2 diperoleh pengoperasian aplikasi dapat berjalan dengan baik selama tidak mendapatkan gangguan layanan internet pada pengguna yang ditandai dengan nilai rata-rata pada (SS) sebesar 146, nilai (S) sebesar 105, nilai (TS) sebesar 17 dan nilai (STS) sebesar 4.75.

Tabel 3. Pertanyaan umpan balik

\begin{tabular}{llcccc}
\hline No & \multicolumn{1}{c}{ Pertanyaan } & $S S$ & $S$ & $T S$ & $S T S$ \\
\hline 1 & Sistem aplikasi menyediakan isi yang sangat sesuai dengan & 69 & 129 & 18 & 56 \\
& kebutuhan & & & & \\
2 & Sistem aplikasi menyediakan isi yang bermanfaat & 180 & 63 & 20 & 9 \\
3 & Sistem aplikasi menyediakan isi yang cukup lengkap & 42 & 194 & 30 & 6 \\
4 & Sistem aplikasi menyediakan isi yang up-to date & 192 & 20 & 40 & 20 \\
\hline & Rata-rata & 121 & 102 & 27 & 22.8 \\
\hline
\end{tabular}

Dari hasil tabel 3 diperoleh hasil yang baik terkait dengan menu-menu dan kemudahan dalam berinteraksi yang disajikan baik oleh penyedia untuk pendidik maupun pendidik untuk peserta didik yang ditandai dengan hasil rata-rata (SS) sebesar 121, nilai (S) sebesar 102, nilai (TS) sebesar 27 dan nilai (STS) sebesar 22.8.

Tabel 4. Pertanyaan personalisasi

\begin{tabular}{llcccc}
\hline No & \multicolumn{1}{c}{ Pertanyaan } & $S S$ & $S$ & $T S$ & STS \\
\hline 1 & $\begin{array}{l}\text { Sistem pembelajaran secara online memungkinan saya untuk } \\
\text { memilih materi yang ingin saya pelajari }\end{array}$ & 149 & 93 & 8 & 22 \\
2 & $\begin{array}{l}\text { Sistem pembelajaran secara online memungkinkan saya } \\
\text { mempelajari materi yang saya butuhkan }\end{array}$ & 30 & 134 & 78 & 30
\end{tabular}


Sosialisasi Penggunaan Aplikasi E-Learning Berbasis Website Di Masa Pandemi Covid-19

\begin{tabular}{clrlrrrr}
3 & $\begin{array}{l}\text { Sistem pembelajaran } \\
\text { pembelajaran saya }\end{array}$ & secara online merekam & kemampuan & 179 & 72 & 12 & 9 \\
\hline 4 & $\begin{array}{l}\text { Sistem pembelajaran secara online mempermudah saya } \\
\text { mendiskusikan pertanyaan kepada para guru }\end{array}$ & 186 & 65 & 12 & 9 \\
\hline Rata-rata & 136 & 91 & 28 & 17.5 \\
\hline
\end{tabular}

Dari hasil tabel 4 diperoleh nilai rata-rata dari (SS) sebesar 136, nilai (S) sebesar 91, nilai (TS) sebesar 28 dan nilai (STS) sebesar 17.5.

Tabel 5. Pertanyaan interaktivitas

\begin{tabular}{cllccccc}
\hline No & \multicolumn{2}{c}{ Pertanyaan } & $S S$ & $S$ & $T S$ & $S T S$ \\
\hline 1 & $\begin{array}{l}\text { Interaktivitas pembelajaran melalui } \\
\text { memberikan rasa nyaman }\end{array}$ & sistem & e-learning & 79 & 138 & 20 & 35 \\
2 & $\begin{array}{l}\text { Interaktivitas pembelajaran melalui } \\
\text { meningkatkan motivasi semangat belajar }\end{array}$ & sistem e- learning & 30 & 168 & 58 & 16 \\
3 & $\begin{array}{l}\text { Interaktivitas pembelajaran melalui sistem e- learning membantu } \\
\text { penguasaan e-learning }\end{array}$ & 193 & 75 & 4 & 0 \\
4 & $\begin{array}{l}\text { Sistem e-learning memudahkan saya untuk dapat mengakses } \\
\text { materi dari guru mata pelajaran }\end{array}$ & 10 & 200 & 40 & 22 \\
\hline Rata-rata & 78 & 145 & 31 & 18.3 \\
\hline
\end{tabular}

Dari hasil tabel 5 diperoleh nilai rata-rata dari interaksi komunikasi yang dihasilkan cukup baik yang ditandai dengan nilai (SS) sebesar 78, nilai (S) sebesar 145, nilai (TS) sebesar 31 dan nilai (STS) sebesar 18.3 .

\section{SIMPULAN}

Kegiatan sosialisasi penggunaan aplikasi e-learning berbasis website yang telah dibuat sebelumnya oleh para peserta didik kejuruan Rekayasa Perangkat Lunak (RPL) yang dipandu oleh pendidik juga Tim PkM. Dengan demikian, tim menghasilkan sebuah karya yang dapat digunakan selama masa pembelajaran online dan atau untuk mendukung pembelajaran antara guru dan siswa di kemudian hari berupa aplikasi pembelajaran online berbasis website. Tentu hal ini akan menjadi sebuah keunggulan khusus yang dapat diperkenalkan kepada sekolah-sekolah lain untuk menggunakan aplikasi tersebut. Pengabdi merasa masih belum dapat memberikan hal yang lebih dalam kegiatan ini, namun kami berharap dengan adanya aplikasi ini akan sangat membantu sekolah dalam memberikan dan menjalankan proses kegiatan belajar mengajarnya. Karena tujuan kami yakni untuk memberikan sebuah karya yang dapat digunakan untuk masa depan berupa sebuah aplikasi pembelajaran online.

\section{UCAPAN TERIMA KASIH}

Pengabdi pengucapkan besar terima kasih kepada LPPM STEBIS Bina Mandiri yang telah memberikan kesempatan untuk dapat memberikan hal yang terbaik kepada SMK Bina Mandiri Multimedia melalui aplikasi online. Juga, kepada Kepala Sekolah SMK Bina Mandiri Multimedia Bapak Eryandi, S.Pd. M.Pd. yang telah memfasilitasi tim untuk dapat melakukan kegiatan pengabdian ini.

\section{DAFTAR PUSTAKA}

[1] H. T. Sihotang, "Pembuatan Aplikasi E-Learning Pada SMK Swasta Pariwisata Imelda," J. Mantik Penusa, vol. 1, no. 2, 2017.

[2] A. Latip, "Peran literasi teknologi informasi dan komunikasi pada pembelajaran jarak jauh di masa pandemi Covid-19," EduTeach J. Edukasi dan Teknol. Pembelajaran, vol. 1, no. 2, pp. 108-116, 2020.

[3] R. N. Haryadi, Anda Rojali, Khumidin, and M. Fauzan, "Sosialisasi Penggunaan Online Shop 
berbasis Website di UMKM Cimanggis," J. Pengabdi. Bina Mandiri, vol. 1, no. 1, pp. 10-16, Jul. 2021, doi: 10.51805/jpmm.v1i1.3.

[4] S. Ameliola and H. D. Nugraha, "Perkembangan media informasi dan teknologi terhadap anak dalam era globalisasi," 2013.

[5] A. Muhson, "Pengembangan media pembelajaran berbasis teknologi informasi," J. Pendidik. Akunt. Indones., vol. 8, no. 2, 2010.

[6] M. R. Arief, "Pemrograman web dinamis menggunakan php dan mysql," Yogyakarta Andi, pp. 7-19, 2011.

[7] Bagas Kurniawan, Ade Ajie Ferizal, and Iskandar, "RANCANG BANGUN GAME BADEX HURDLE BERBASIS MULTIMEDIA MENGGUNAKAN MACROMEDIA FLASH 8," TEKNOSAINS J. Sains, Teknol. dan Inform., vol. 8, no. 1, 2021, doi: 10.37373/tekno.v8i1.71.

[8] M. I. Saad, Otodidak Web Programming: Membuat Website Edutainment. Elex Media Komputindo, 2020.

[9] A. Surya, F. Azharul, W. Wilarso, M. Idris, Y. Z. Azziqi, and I. H. Retno, "Improving High School and Vocational School Teachers in Writing Skill," J. Dedik., vol. 17, no. 1, p. 64, 2020, doi: 10.22219/dedikasi.v17i1.12021.

[10] Iskandar and Umar Tsani Abdurrahman, "IMPLEMENTASI APLIKASI ASISTENSI GURU DI KELAS DENGAN TEKNIK GEOFENCING BERBASIS ANDROID," INFOTECH J. Inform. Teknol., vol. 1, no. 1, 2020, doi: 10.37373/infotech.v1i1.32.

[11] A. Murtani, "Sosialisasi Gerakan Menabung," Sindimas, vol. 1, no. 1, pp. 279-283, 2019.

[12] D. Herdiana, "Sosialisasi Kebijakan Publik: Pengertian dan Konsep Dasar," J. Ilm. Wawasan Insa. Akad., vol. 1, no. 3, pp. 13-26, 2018.

[13] J. Maknunah, I. D. Mumpuni, L. S. Rahmawati, and R. Widayanti, "Microsoft Excel Training for Data Processing for Vocational High School Students," vol. 18, no. 2, pp. 20-26, 2021.

[14] A. F. Hery Soegiharto and Sudarman, "Pendampingan Pembelajaran Keterampilan Secara Daring di Pondok Pesantren Tarbiyatul Iman Malang," BEMAS J. Bermasyarakat, vol. 2, no. 1, 2021, doi: 10.37373/bemas.v2i1.131.

[15] Sudirman, "MANAJEMEN DATA PENDIDIKAN ANAK SECARA REAL-TIME DENGAN OPEN-SOURCE SMART REGISTER PLATFORM (OpenSRP)," INFOTECH J. Inform. Teknol., vol. 2, no. 1, 2021, doi: 10.37373/infotech.v2i1.110. 